\title{
Effect of Irrigating Agitation after Root End Preparation on the Wall Cleaning and Bond Strength of Calcium Silicate Material in Retrograde Obturation
}

\author{
Yahir Muñoz Valencia ${ }^{1}$ Gislene Cristina Vertuann ${ }^{1, \oplus} \quad$ Murilo Priori Alcalde ${ }^{1} \quad$ Rodrigo Ricci Vivan ${ }^{1}$ \\ Marcus Vinícius Reis Só ${ }^{2}$ Marco Antonio Hungaro Duarte ${ }^{1}$
}

${ }^{1}$ Department of Operative Dentistry, Endodontics and Dental Materials, Bauru School of Dentistry, University of São Paulo, Bauru, São Paulo, Brazil

2Department of Dentistry, University Federal of the Rio Grande do Sul, Porto Alegre, Rio Grande do Sul, Brazil

\begin{abstract}
Address for correspondence Gislene Cristina Vertuan, DDS, MSc, Department of Operative Dentistry, Bauru School of Dentistry, University of São Paulo, Alameda Dr. Octávio Pinheiro Brisolla, 9-75 - Jardim Brasil, Bauru, SP 17012-901, São Paulo, Brazil (e-mail: gislenevertuan@usp.br).
\end{abstract}

Eur J Dent 2021;15:707-713.

\begin{abstract}
Keywords

- smear layer

- bond strength

- root-end cavity

- retrograde filling

- scanning electron microscopy

- push-out

Objective This study aimed to evaluate the cleaning efficacy of irrigant activation with a new ultrasonic tip in root-end preparations and to determine its influence on the bond strength of calcium silicate-based material.

Materials and Methods Maxillary canines were prepared and filled, and their root ends resected. Root-end cavities were ultrasonically prepared and randomly distributed into four groups according to the final irrigation protocols: G1 (ultrasonic irrigation $[\mathrm{UI}]+$ saline solution [SS]), G2 (syringe irrigation [SI] + SS), G3 (UI + ethylenediaminetetraacetic acid [EDTA]), and G4 (SI + EDTA). Cleaning efficacy analysis employed 72 specimens $(n=18)$ split longitudinally for imaging of the same areas by scanning electron microscopy (SEM). The percentage of dentinal tubules opened before and after irrigation was used as evaluation parameter. Push-out testing employed 40 specimens $(n=10)$ sectioned apical region perpendicularly, which slice was placed on a testing machine for the bond strength measurement and failure mode was assessed by SEM. The data were statistically analyzed ( $\alpha \leq 0.05)$.

Results G3 (UI + EDTA) removed the smear layer more effectively, showed the best tubule opening $(p<0.05)$, and presented the highest mean bond strength values $(p<0.05)$. Failure modes were predominantly adhesive, except for the G3 (UI + EDTA) group, in which they were mainly mixed (80\%).

Conclusion The results of this study suggest that EDTA $17 \%$ agitation promoted better cleaning and smear layer removal, improving the push-out bond strength of calcium silicate material in retrograde obturation.
\end{abstract}

\section{Introduction}

Surgical endodontics is a viable and reliable treatment option for teeth with persistent radiographic and/or clinical signs and symptoms after orthograde treatment failure, and it is almost always performed when a lesion of endodontic origin is present and these lesions are always associated with the presence of bacteria. ${ }^{1}$ The microsurgery has evolved published online July 24, 2021
DOI https://doi.org/

$10.1055 / \mathrm{s}-0041-1729454$ ISSN 1305-7456
(C) 2021. European Journal of Dentistry.

This is an open access article published by Thieme under the terms of the Creative Commons Attribution-NonDerivative-NonCommercial-License, permitting copying and reproduction so long as the original work is given appropriate credit. Contents may not be used for commercial purposes, or adapted, remixed, transformed or built upon. (https://creativecommons.org/licenses/by-nc-nd/4.0/). Thieme Medical and Scientific Publishers Pvt. Ltd. A-12, 2nd Floor, Sector 2, Noida-201301 UP, India 
advantageously over time in terms of quality of clinical procedures to attain the goal of periapical healing. ${ }^{2}$

Ultrasonic retrotips represent one of the most relevant advancements in endodontic surgery, and several experimental studies have shown its ability to produce more centered, parallel, deeper, and conservative root-end preparations, ${ }^{3}$ which improves the sealing ability and marginal fit of root-end filling materials, increasing the success rate of endodontic surgery by $91.6 \%{ }^{4}$ However, the presence of smear layer could make this goal more difficult and challenging. ${ }^{5}$

During apical surgery procedures such as apicectomy and retrograde cavity, for example, the cut performed by drills or ultrasonic retrotips produces smear layer; besides, being a physical barrier may contain microorganisms, pulp tissue remains, allowing survival and maintenance or proliferation of bacteria inside the dentinal tubules. ${ }^{6}$ Likewise, according to Gutmann et al, ${ }^{7}$ the smear layer was identified containing particles of calcified tissue, tissue debris, blood cells, and microorganisms, with the possibility of adding remnants of filling material such as endodontic sealers or gutta percha in cases of root-end preparation.

The accumulation of hard tissue debris in form of smear layer is considered a failure factor ${ }^{5}$ during root-end preparation. Some surgical reports have shown that residual bacteria and biofilm infection could potentially recolonize untouched walls, complex networks of ramifications, and lateral canals show an outstanding ability to adapt and persist in a hostile environment. ${ }^{8,9}$

Many authors defend the complete removal of this smear layer in conventional treatments, during disinfection procedures in orthograde endodontics, so that way it seems reasonable that for surgical endodontics, these procedures may be just as convenient due to the risk of failure in treatment $^{1,10}$ as described the removal of the smear layer in retrograde cavities produced with drills, in surgical endodontics, by Gutmann et al. ${ }^{7}$

Moreover, a clean dentine substrate with patent tubules could facilitate the penetration of calcium silicate-based material into dentinal tubules, increasing the formation of tag-like structures at the cement-dentine interface and higher micromechanical retention of the root-end filling material with the subsequent improvement of the bond strength could be promoted. ${ }^{11}$ Among the physicochemical properties, adhesive resistance to intraradicular dentin is of particular interest because root-end filling materials must be able to remain adapted to the dentin walls when the teeth are subjected to mechanical forces occurring during function or operative and surgical procedures. ${ }^{12}$

Therefore, the smear layer produced by drills or microsurgical ultrasonic retrotips may be contaminated with microorganisms, and its presence could interfere in endodontic treatment success, ${ }^{6,7}$ as well as interfere in a better penetrability, adaptation, and adhesiveness of retro-end filling material. ${ }^{11,12}$

Although microsurgical retrotips have simplified root-end preparation, ${ }^{13}$ the surgical irrigation approach is still performed by using a conventional needle coupled to a syringe and this syringe irrigation (SI) allows suitable irrigation control over the penetration of the needle and outflow of the irrigant by positive apical pressure. ${ }^{14,15}$

It is known that the acoustic streaming of ultrasonic irrigation (UI) has shown greater efficiency in removing dentine debris, maximizing the antimicrobial effect of conventional irrigation, ${ }^{16}$ and this irrigant activation technique improves the adhesiveness, compressive strength, surface microhardness, and sealing ability of some root-end filling materials, ${ }^{17}$ but the use of UI in apical surgeries has not been well established. The previous studies suggest that in endodontic surgery, additional technological alternatives to smear layer removal, bacteria reduction, and biofilm disruption should be investigated.

Recently, a novel root-end ultrasonic tip for surgical endodontics irrigation has been developed. Mini Irrisonic (Helse Ultrasonic, São Paulo, Brazil) is a stainless-steel insert with 65-degree inclination, approximately $5.0 \times 0.2 \times 0.1 \mathrm{~mm}$ in length, diameter, and taper, respectively, and a noncutting blade ( - Fig. 1 ). This tip was designed to active irrigating solutions on root-end preparations to remove the smear layer and dentine debris after root-end cavity preparations. No studies have reported the influence of ultrasonics on the final irrigant activation technique in endodontic surgery.

So, the purpose of this study was to analyze in vitro the effect of irrigant activation with this new tip after root-end preparations with regard the efficacy in smear layer removal and to its impact on the bond strength. The null hypothesis was that there is no significant difference between conventional and ultrasonic final root-end irrigation in smear layer removal and in bond strength of a calcium silicate-based material.

\section{Materials and Methods}

This study was approved by the local Research Ethics Committee (process 94400318.2.0000.5417).

\section{Sample Selection}

In total, 112 freshly extracted human single-rooted maxillary canines with fully formed apices and similar root morphology was obtained and stored in 0 to $1 \%$ thymol solution at $5^{\circ} \mathrm{C}$. The crowns were sectioned and standardized below the cementoenamel junction by using a double-faced diamond disc (7020; KG Sorensen, SP, Brazil). Apical patency was created by inserting a stainless-steel K-file size 10/0.02 (Dentsply/Maillefer, Ballaigues, Switzerland) until its tip was seen at the apical foramen by using a stereomicroscope.

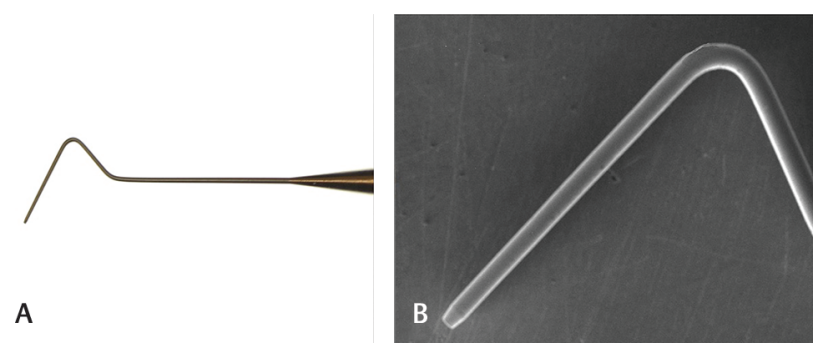

Fig. 1 Photograph and scanning electron microscopy images of the Mini Irrisonic insert. 


\section{Root Canal Preparation}

The root canals were prepared with Reciproc instruments R25 and R40 (VDW, Munich, Germany), respectively, in reciprocating motion by using a Silver motor (VDW, Munich, Germany). Irrigation was performed with $2 \mathrm{~mL}$ of $2.5 \% \mathrm{NaOCl}$ between each file size and final rising with $5 \mathrm{~mL}$ of $17 \%$ EDTA and with $5 \mathrm{~mL}$ of $2.5 \% \mathrm{NaOCl}$ for smear layer removal. The canals were then dried with absorbent paper points and filled by using the single-cone technique with R40 gutta-percha cones (MKLife, RS, Brazil) and Sealer Plus sealer (MKLife, RS, Brazil). Afterward, all roots were stored at $37^{\circ} \mathrm{C}$ in $100 \%$ humidity for 1 week.

\section{Root-End Cavity Preparation}

Root-end resection was performed at 90 degrees on the long axis of the roots removing $3 \mathrm{~mm}$ of the apex by using a low-speed diamond wafering saw (Isomet 1000, Buehler, Lake Bluff, Illinois, United States) with $125 \times 0.35 \times$ 12.7 dimensions, rotated at 250 to $300 \mathrm{rpm}$ under continuous water irrigation. Root-end cavity preparations were performed with an ultrasonic retrotip P1 (Helse Ultrasonics, SP, Brazil) with $3.0 \times 1.5 \mathrm{~mm}$ in depth and in diameter mounted on an ultrasonic unit (Varios 350, NSK Nakanishi, Kanuma, Japan) with a low-power setting (20\%).

\section{Scanning Electron Microscope Analysis}

Seventy-two specimens were selected for analysis of smear layer removal according to each final irrigation protocol. After root-end preparation, longitudinal grooves were created along the buccal and lingual surfaces without reaching the root canal. The specimens with root-end cavities oriented upward were embedded and molded in a metallic muffle containing a polysiloxane impression material Speedex (Coltene, Whaledent, New York, New York, United States) to prevent the irrigant from leaking during the final irrigation protocols. $^{18}$

Thereafter, the specimens were removed from the muffles and split longitudinally by using a modified cement spatula Duflex (SS White, RJ, Brazil), positioned into each groove, generating two halves. Both segments were joined together, secured with a light-curing resin Top Dam (FGM, SC, Brazil) and rubber band ligation, placed into the mold, and the muffle was repositioned.

The specimens $(n=72)$ were randomly divided into four groups ( $n=18)$ (http://www.random.org) based on the presence or absence of UI and 17\% ethylenediaminetetraacetic acid (EDTA) as final irrigation protocol: G1 (UI + SS), G2 (SI + SS), G3 (UI + 17\% EDTA), and G4 (SI + 17\% EDTA).

Each solution was used in three cycles $(5 \mathrm{~mL} / 20$ seconds, totaling 1 minute in contact with the dentine surface. After each cycle of 20 seconds, the solution was renewed. Additionally, in G3 (UI + EDTA) and G4 (SI + EDTA) groups, $5 \mathrm{~mL} / 20$ seconds of saline solution was employed to remove residual EDTA and to standardize $20 \mathrm{~mL}$ of final irrigant volume per group. Likewise, in saline solutions groups G1 (UI + SS) and G2 (SI + SS), $20 \mathrm{~mL}$ were used as the total irrigation volume. Ultrasonic activation was performed at a power setting of $20 \%, 0.5 \mathrm{~mm}$ shorter from the bottom of the root-end cavity and driven toward the buccal groove. SI was achieved by using a syringe with a 30-G open-ended tip needle Navitip (Ultradent Products, Salt Lake City, Utah, United States), positioned on the top of the root-end cavity. In the groups without activation, EDTA or saline solution was maintained in the root-end cavity for 20 seconds in each cycle, total three cycles. In the same way, a final irrigation with $5 \mathrm{~mL}$ of saline solution was performed to standardize final volume per group.

Imaging of the dentinal tubules was based on the scoring system proposed by Hülsmann, Rümmelin e Schäfers, ${ }^{19}$ which was modified and expressed as percentages: $0=0 \%, 1=1-25 \%, 2=26-50 \%, 3=51-75 \%, 4=76-99 \%$, and $5=100 \%$, according to the number of dentinal tubules exposed. The evaluations were performed by two calibrated examiners blinded to the experimental groups. In addition, a digital grid divided into 100 squares was used over the images to improve the quantification of visible dentinal tubules, which were exported in slice format into Microsoft Office PowerPoint (Microsoft, Redmond, Washington, D.C., United States). ${ }^{20}$ Three equidistant photomicrographs were acquired from each hemisection (segments $\mathrm{A}, \mathrm{B}$, and C; - Fig. 2) by environmental scanning electron microscopy (SEM) by using PSEM Express (Aspex, Delmont, Pennsylvania, United States) operating at 15 to $20 \mathrm{kV}$ and $\times 250$ magnification. The specimens were evaluated at two different time intervals, pre- and postirrigation, following the same parameters described previously.

\section{Push-Out Testing}

Forty specimens remaining were selected to analyze the bond strength according to each final irrigation protocol. The four experimental groups $(n=10)$ were randomly distributed in the same manner as described previously (http://www.random.org). At the end of the final irrigation protocols, the cavities were dried with absorbent points and filled with an experimental calcium silicate-based material. Portland cement with addition of bismuth oxide in 5:1 ratio was employed in association with distilled water $(80 \%)$ and propylene glycol $(20 \%)$ as vehicle. ${ }^{21}$ Each filled root-end cavity was compacted with a small plunger, the excess cement was removed, and the specimens were stored in an incubator at $37^{\circ} \mathrm{C}$ in the presence of humidity for 7 days.

The apical portion of each specimen was sectioned perpendicularly to the long axis into $2.0 \pm 0.1 \mathrm{~mm}$ thick

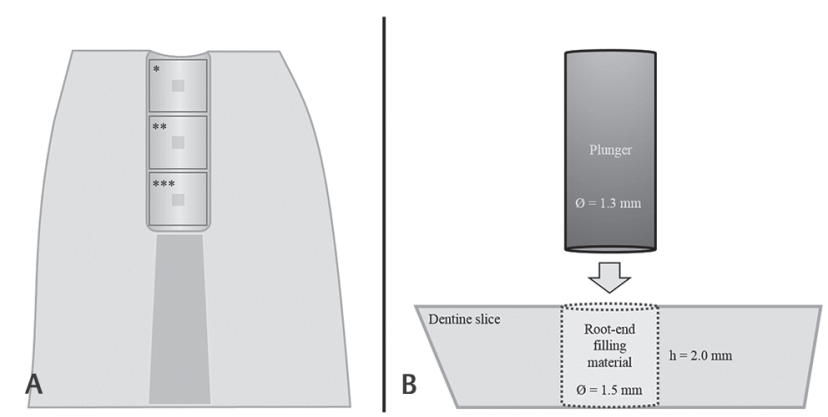

Fig. 2 (A) Representative areas for scanning electron microscopy analysis: segments $A^{*}, B^{* *}$, and $C^{* * *}$. (B) Push-out bond strength test diagram. 
slices with a low-speed diamond wafering saw Isomet 1000 (Buehler, Lake Bluff, Illinois, United States) at 250 to $300 \mathrm{rpm}$ under continuous water irrigation. Each surface was polished by using 220- and 600-grit sandpaper until the entire material/dentine interface could be observed. ${ }^{22}$

The push-out bond strength was measured by using a universal testing machine Instron 3342 (Instron, Canton, Massachusetts, United States) with a $5-\mathrm{kN}$ load cell at a speed of $1 \mathrm{~mm} / \mathrm{min}-1$. The fillings were loaded progressively by using a cylindrical stainless-steel plunger with $1.3 \mathrm{~mm}$ in diameter, ${ }^{22}$ and the force was applied from the cervical to the apical region, because parallel root-end cavity preparation, with the smaller base of the slice in contact with the stainless-steel supporting holder (-Fig. 2).

While there is no accepted standard size, some authors have recommended a diameter ratio of approximately $85 \%$ between the plunger and filling material. ${ }^{22}$ In the present study, a $1.5 \mathrm{~mm}$ root-end cavity preparation was performed, whereas a 1.3-mm plunger diameter was selected.

The values were obtained in Newtons $(\mathrm{N})$ and transformed to megapascals (MPa). The recorded value was divided by the surface adhesion filling area, calculated by formula for the lateral surface area of a cylinder: $2 \pi \mathrm{rh}$, where $\pi=3.14, \mathrm{r}$ is the radius of the root canal and $h$ is the thickness of the dentine slice. $^{22}$

The fractographic analysis was performed by SEM at $\times 85$ magnification to determine the failure mode, which was classified as adhesive, cohesive, or mixed.

\section{Statistical Analysis}

Cohen's kappa coefficient was used to measure intra- and interrater reliability for SEM assessment. The KruskalWallis and Dunn's tests for between-group comparisons and Friedman and Dunn's tests were used for within-group comparisons. The Shapiro-Wilk test was used to determine the normal distribution of push-out bond strength data. ANOVA and Tukey's tests were used for multiple and individual comparisons. The statistical analysis was performed by GraphPad Prisma 5 (GraphPad Software, San Diego, California, United States) with significance level set at $5 \%$.

\section{Results}

- Table 1 displays the distribution and percentage of smear layer scores. In all groups, the highest percentage of opened dentinal tubule areas was found in the G3 (UI + EDTA) group, followed by the G4 (SI + EDTA), G1 (UI + SS), and G2 (SI + SS) groups, respectively $(p<0.05)$.

For between-group comparison, segments A and B of G3 $(\mathrm{UI}+$ EDTA) exhibited the highest amount of smear layer removal, followed by the G4 (SI + EDTA) group ( $p<0.05)$. Segment C of G3 (UI + EDTA) and G4 (SI + EDTA) showed a similar amount of remnant smear layer $(p>0.05)$. The within-group comparisons did not reveal any statistically significant differences $(p>0.05)$. - Fig. 3 presents the representative SEM images in the three segments according to each group.
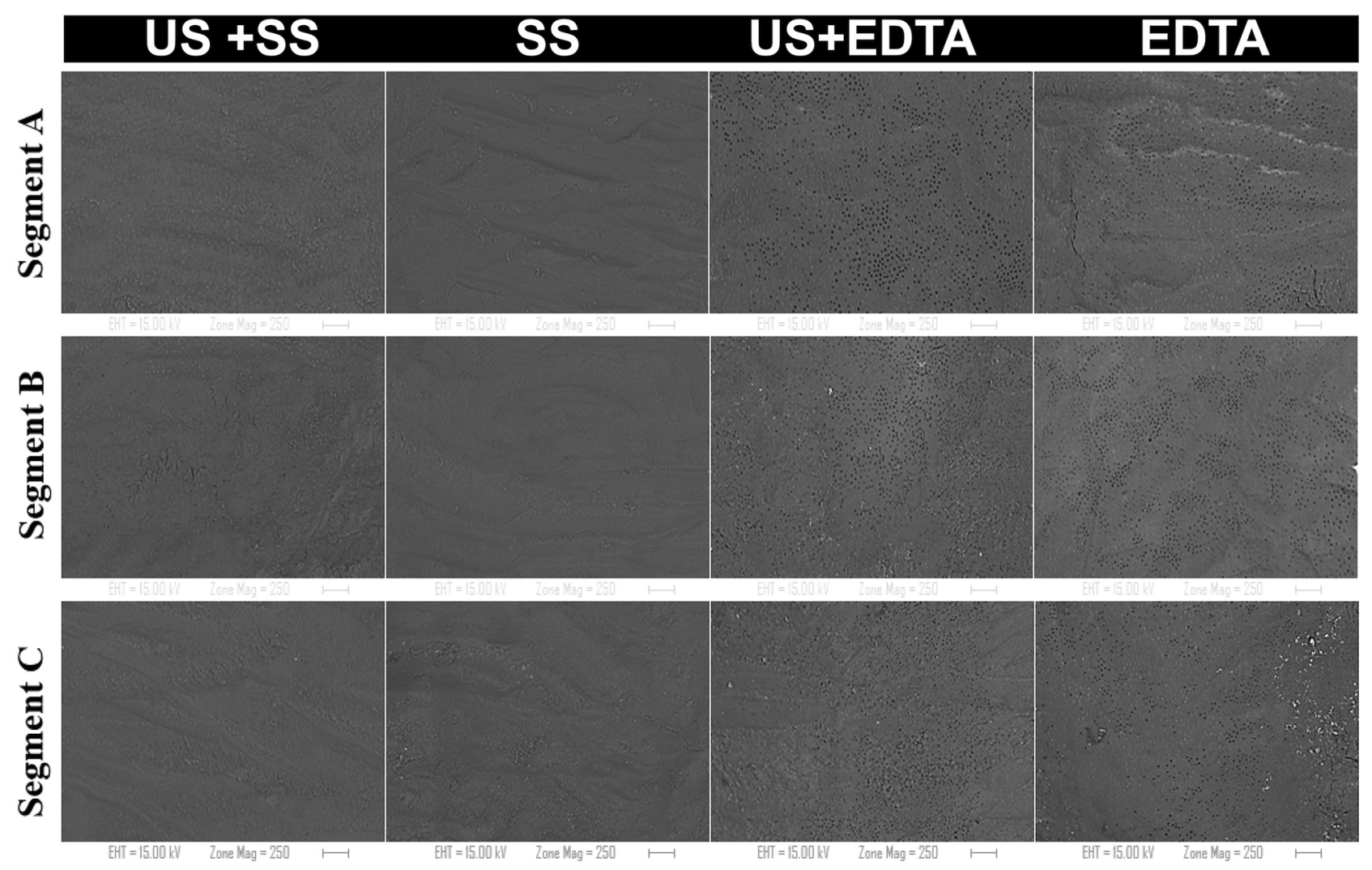

Fig. 3 Representative scanning electron microscopy images of segments $A$, B, and $C$ showing the different final irrigation solutions $(\times 250$ magnification). 
Table 1 Median, minimum, and maximum of the score of the smear layer removal according to the studied groups

\begin{tabular}{|l|l|l|l|l|}
\hline & \multicolumn{3}{|l|}{ Segments } \\
\hline Group $(\boldsymbol{n}=18)$ & Total & Segment A & Segment B & Segment C \\
\hline G1 (UI + SS) & $0(0-4)^{\mathrm{C}}$ & $0(0-1)^{\mathrm{Ca}}$ & $0(0-3)^{\mathrm{Ca}}$ & $0(0-4)^{\mathrm{Ba}}$ \\
\hline G2 (SI + SS) & $0(0-1)^{\mathrm{C}}$ & $0(0-1)^{\mathrm{Ca}}$ & $0(0-0)^{\mathrm{Ca}}$ & $0(0-1)^{\mathrm{Ba}}$ \\
\hline G3 (UI + EDTA) & $2(0-4)^{\mathrm{A}}$ & $2(0-4)^{\mathrm{Aa}}$ & $3(0-4)^{\mathrm{Aa}}$ & $2(1-4)^{\mathrm{Aa}}$ \\
\hline G4 (SI + EDTA) & $1(0-4)^{\mathrm{Ba}}$ & $1(0-4)^{\mathrm{Ba}}$ & $1(0-4)^{\mathrm{Ba}}$ & $1(0-4)^{\mathrm{Aa}}$ \\
\hline
\end{tabular}

Abbreviations: EDTA, ethylenediaminetetraacetic acid; SI, syringe irrigation; SS, saline solution; UI, ultrasonic irrigation.

Note: Different superscript capital letters in each column indicate intergroup statistically significant differences $(p<0.05)$. Different superscript lowercase letters in each row indicate intragroup statistically significant differences $(p<0.05)$.

Table 2 Mean and standard deviation values of the bond strength in MPa and type of failure according to the studied groups

\begin{tabular}{|l|l|l|l|}
\hline & \multicolumn{2}{|l|}{ Failure mode (\%) } \\
\hline Group $(\boldsymbol{n}=10)$ & Push-out (Mpa) & Adhesive & Mixed \\
\hline G1 (UI + SS) & $2.27 \pm 0.39^{\mathrm{C}}$ & 60 & 40 \\
\hline G2 (SI + SS) & $2.25 \pm 0.38^{\mathrm{C}}$ & 70 & 30 \\
\hline G3 (UI + EDTA) & $6.42 \pm 0.69^{\mathrm{A}}$ & 20 & 80 \\
\hline G4 (SI + EDTA) & $2.86 \pm 0.27^{\mathrm{B}}$ & 70 & 30 \\
\hline
\end{tabular}

Abbreviations: EDTA, ethylenediaminetetraacetic acid; SI, syringe irrigation; SS, saline solution; UI, ultrasonic irrigation.

Note: Different superscript capital letters in each column indicate intergroup statistically significant differences $(p<0.05)$.

- Table 2 presents the mean push-out bond strength values (MPa), standard deviation, and percentage of fracture resistance. G3 (UI + EDTA) showed the highest push-out bond strength values, with statistically significant differences from the other groups $(p<0.05)$. Other differences occurred in the comparison of G4 (SI + EDTA) with G2 (SI + SS) and G1 (UI + SS) groups $(p<0.05)$.

The fractographic analysis showed no significant differences among failure modes $(p>0.05)$. The mixed failure mode was the most prevalent in G3 (UI + EDTA; 80\%). Cohesive failure was not observed in any group.

\section{Discussion}

The null hypothesis of this study was rejected because the results showed that there was a statistically significant difference in the cleaning and smear layer removal and in the push-out bond strength of the root-end filling material between irrigation protocols.

There are no studies addressing the impact of use microsurgical ultrasonic retrotips in endodontic surgery, given that it is opportune to carry out a study that evaluated final irrigation protocols, with regard to the cleaning of the dentinal walls and the adhesiveness of the material. It can be observed that our results are in agreement with those of other studies that investigated the effect of ultrasonically activated EDTA in conventional treatments, during disinfection procedures in orthograde endodontics. ${ }^{23-25}$

The results showed that the novel ultrasonic tip for final irrigant activation, when associated with EDTA, was significantly better than the syringe irrigation at smear layer removal, which affected positively the bond strength of the root-end filling material. Although EDTA can interfere in the hydration of calcium silicate-based cements, ${ }^{26}$ in the present study, abundant irrigation with saline solution was used to remove EDTA. This enhanced cleaning efficacy could be attributed to acoustic streaming, which increases the hydrodynamic flow of the irrigant, creating higher mechanical stress on the smear layer walls, ${ }^{27}$ corroborating once more the advantages of ultrasonic activation.

The comparison of segments showed that the demineralization pattern with EDTA was different for each technique. SI showed the most uniform scoring distribution, and this could be attributed to the better control of irrigant pressure, although with a limited penetration depth because of the weaker mechanical flushing. ${ }^{28}$ In comparison, UI showed a higher irrigant flow, which was more effective in removing the smear layer, although with a less homogeneous scoring distribution pattern. Another possible explanation could be related to the area of greatest magnitude of oscillation, ${ }^{27,29}$ which could match with segment B of the root-end cavity preparation, as shown in the present study.

In the push-out testing, our findings showed that G1 (UI + SS), G2 (SI + SS), and G4 (SI + EDTA) groups are in agreement with the findings of previous studies. ${ }^{18,25}$ In fact, the diminished bond strength of these groups could be attributed to the higher amount of remnant smear layer, reducing the contact surface at the material-dentine interface and avoiding intratubular formation of tag-like structures, which could interfere with the biomineralization process. ${ }^{11,29}$ Additionally, heterogeneous particle sizes of calcium silicate-based materials could interfere with the hydraulic properties of the material, decreasing effective micromechanical retention. ${ }^{30}$

The significant improvement of the bond strength by three times in the G3 (UI + EDTA) group could be attributed to a higher percentage of smear layer removal and open dentinal tubules, which increases micromechanical retention and the addition of $20 \%$ propylene glycol to the calcium silicate-based cement enhances both handling and flowability properties and reduces the film thickness of the 
material. ${ }^{31}$ Therefore, it simplifies and promotes better distribution of the filling material within the dentinal tubules and irregularities of the root-end preparation, improving the push-out bond strength. ${ }^{32}$

The inspection of root slices revealed that fracture modes were mainly adhesive except for the G3 (UI + EDTA) group, in which they were mixed. This could be attributed to the hydrophilic reaction of calcium silicate-based cement particles, which grows and expands in the form of nodes in moist environments. ${ }^{33}$ Thus, the greater the number of cleaned surfaces and exposed dentinal tubules, the greater and deeper the coalescence with nodes from other cement particles. It appears that the mixed failure mode showed better marginal adaptation of the root-end filling material to dentine walls. The results of the other three groups are in agreement with those of another study. ${ }^{32}$

EDTA was selected because has been effective for cleanliness and smear layer removal as final irrigation solution in comparison with other substances. ${ }^{33}$ Moreover, it has some antibacterial effect $^{34}$ with satisfactory tissue response in short periods of time. ${ }^{35}$ Even, it could stimulate the release of grown factors and increases cell attachment to the dentin surface, ${ }^{36}$ justifying its use in the present study. Both groups treated with EDTA exhibited significant smear layer removal, regardless of the final irrigation technique performed. This result shows that were a synergism between use of the irrigant EDTA in association with ultrasonic agitation promoting a better cleaning and smear layer removal.

Mineral trioxide aggregate (MTA) has been accepted as an appropriate root-end filling material following ultrasonic root-end preparation due to its properties, such as biocompatibility, bioactivity, hard tissue conductive-inductive, antimicrobial, and as well as its ability to set in the presence of moisture, having been used in areas with bleeding. ${ }^{37}$ Even though several calcium silicate-based materials have been developed to date, Portland cement was chosen due to its composition very similar to MTA. ${ }^{38-40}$

The similarity between MTA and Portland cement has been demonstrated regarding the composition of the basic elements, antimicrobial action, biologic behavior and physical, and chemical properties. ${ }^{40}$ Considering the optimum radio proposed by Duarte et $\mathrm{al}^{31}$ and Salem et $\mathrm{al}^{32}$ this study employed Portland cement with addition of bismuth oxide in 5:1 ratio in association with $80 \%$ distilled water (DW); $20 \%$ propylene glycol (PG) as vehicle and the results of push-out bond strength test of the DW/PG group by Salem et $\mathrm{al}^{32}$ were similar to our G1 (UI + SS) and G2 (SI + SS) groups.

Some studies have already shown that the association of Portland cement association with distilled water (80\%) and propylene glycol (20\%) improves handling, setting time, sealing ability, flowability, $\mathrm{pH}$, calcium ions release, and increases its push-out bond strength to dentin. ${ }^{21,31,32}$ This could explain the increased push-out bond strength in the G3 (UI + EDTA) group due to the better adaptation of the filling material and the lower gaps formation inside the root-end cavities. Thus, smear layer removal in association with ultrasonic activation of the irrigant could promote better marginal adaptation.

\section{Conclusion}

While considering the limitations of this in vitro study, it can be concluded that the agitation of the EDTA $17 \%$ promoted greater removal of the smear layer. In addition, this higher percentage of dentinal tubule exposure demonstrated a positive effect on push-out bond strength of the retrograde root filling to the root dentine in root-end preparations.

\section{Funding}

This study was financed in part by the Coordenação de Aperfeiçoamento de Pessoal de Nível Superior - Brazil (CAPES) - Finance Code 001 and the São Paulo Research Foundations (FAPESP) - Process 2017/22364-5.

\section{Conflict of Interest}

None declared.

\section{References}

1 Chan S, Glickman GN, Woodmansey KF, He J. Retrospective analysis of root-end microsurgery outcomes in a postgraduate program in endodontics using calcium silicate-based cements as root-end filling materials. J Endod 2020;46(3):345-351

2 Çalışkan MK, Tekin U, Kaval ME, Solmaz MC. The outcome of apical microsurgery using MTA as the root-end filling material: 2- to 6-year follow-up study. Int Endod J 2016;49(3):245-254

3 Camargo Villela Berbert FL, de Faria-Júnior NB, TanomaruFilho M, et al. An in vitro evaluation of apicoectomies and retropreparations using different methods. Oral Surg Oral Med Oral Pathol Oral Radiol Endod 2010;110(4):e57-e63

4 Rosales-Leal JI, Olmedo-Gaya V, Vallecillo-Capilla M, Luna-del Castillo JD. Influence of cavity preparation technique (rotary vs. ultrasonic) on microleakage and marginal fit of six end-root filling materials. Med Oral Patol Oral Cir Bucal 2011;16(2):e185-e189

5 Torabinejad M, Handysides R, Khademi AA, Bakland LK. Clinical implications of the smear layer in endodontics: a review. Oral Surg Oral Med Oral Pathol Oral Radiol Endod 2002;94(6):658-666

6 Orstavik D, Haapasalo M. Disinfection by endodontic irrigants and dressings of experimentally infected dentinal tubules. Endod Dent Traumatol 1990;6(4):142-149

7 Gutmann JL, Saunders WP, Nguyen L, Guo IY, Saunders EM. Ultrasonic root-end preparation. Part 1. SEM analysis. Int Endod J 1994;27(6):318-324

8 Ricucci D, Loghin S, Siqueira JF Jr. Exuberant Biofilm infection in a lateral canal as the cause of short-term endodontic treatment failure: report of a case. J Endod 2013;39(5):712-718

9 Arnold M, Ricucci D, Siqueira JF Jr. Infection in a complex network of apical ramifications as the cause of persistent apical periodontitis: a case report. J Endod 2013;39(9):1179-1184

10 Torabinejad M, Khademi AA, Babagoli J, et al. A new solution for the removal of the smear layer. J Endod 2003;29(3):170-175

11 Reyes-Carmona JF, Felippe MS, Felippe WT. The biomineralization ability of mineral trioxide aggregate and Portland cement on dentin enhances the push-out strength. J Endod 2010;36(2):286-291

12 Marques JHS, Silva-Sousa YTC, Rached-Júnior FJA, et al. New methodology to evaluate bond strength of root-end filling materials. Braz Dent J 2015;26(3):288-291

$13 \mathrm{Kim}$ S, Kratchman S. Modern endodontic surgery concepts and practice: a review. J Endod 2006;32(7):601-623

14 Leoni GB, Versiani MA, Silva-Sousa YT, Bruniera JF, Pécora JD, Sousa-Neto MD. Ex vivo evaluation of four final irrigation 
protocols on the removal of hard-tissue debris from the mesial root canal system of mandibular first molars. Int Endod J 2017;50(4):398-406

15 Alakshar A, Saleh ARM, Gorduysus MO. Debris and smear layer removal from oval root canals comparing XP-Endo Finisher, EndoActivator, and manual irrigation: A SEM evaluation. Eur J Dent 2020;14(4):626-633

16 Căpută PE, Retsas A, Kuijk L, Chávez de Paz LE, Boutsioukis C. Ultrasonic irrigant activation during root canal treatment: a systematic review. J Endod 2019;45(1):31-44.e13

17 Basturk FB, Nekoofar MH, Gunday M, Dummer PM. Effect of varying water-to-powder ratios and ultrasonic placement on the compressive strength of mineral trioxide aggregate. J Endod 2015;41(4):531-534

18 Martins Justo A, Abreu da Rosa R, Santini MF, et al. Effectiveness of final irrigant protocols for debris removal from simulated canal irregularities. J Endod 2014;40(12):2009-2014

19 Hülsmann M, Rümmelin C, Schäfers F. Root canal cleanliness after preparation with different endodontic handpieces and hand instruments: a comparative SEM investigation. J Endod 1997;23(5):301-306

20 Rodrigues CT, Duarte MAH, Guimarães BM, Vivan RR, Bernardineli N. Comparison of two methods of irrigant agitation in the removal of residual filling material in retreatment. Braz Oral Res 2017;31:e113

21 Marciano MA, Guimarães BM, Amoroso-Silva P, Camilleri J, Hungaro Duarte MA. Physical and chemical properties and subcutaneous implantation of mineral trioxide aggregate mixed with propylene glycol. J Endod 2016;42(3):474-479

22 Vivan RR, Guerreiro-Tanomaru JM, Bernardes RA. Reis JM, Hungaro Duarte MA, Tanomaru-Filho M. Effect of ultrasonic tip and root-end filling material on bond strength. Clin Oral Investig 2016;20(8):2007-2011

23 Lui JN, Kuah HG, Chen NN. Effect of EDTA with and without surfactants or ultrasonics on removal of smear layer. J Endod 2007;33(4):472-475

24 Chopra S, Murray PE, Namerow KN. A scanning electron microscopic evaluation of the effectiveness of the F-file versus ultrasonic activation of a K-file to remove smear layer. J Endod 2008;34(10):1243-1245

25 Kuah HG, Lui JN, Tseng PS, Chen NN. The effect of EDTA with and without ultrasonics on removal of the smear layer. J Endod 2009;35(3):393-396

26 Lee YL, Lin FH, Wang WH, Ritchie HH, Lan WH, Lin CP. Effects of EDTA on the hydration mechanism of mineral trioxide aggregate. J Dent Res 2007;86(6):534-538

27 Verhaagen B, Boutsioukis C, van der Sluis LW, Versluis M. Acoustic streaming induced by an ultrasonically oscillating endodontic file. J Acoust Soc Am 2014;135(4):1717-1730
28 Gu LS, Kim JR, Ling J, Choi KK, Pashley DH, Tay FR. Review of contemporary irrigant agitation techniques and devices. J Endod 2009;35(6):791-804

29 Reyes-Carmona JF, Felippe MS, Felippe WT. Biomineralization ability and interaction of mineral trioxide aggregate and white portland cement with dentin in a phosphate-containing fluid. J Endod 2009;35(5):731-736

30 Dammaschke T, Gerth HU, Züchner H, Schäfer E. Chemical and physical surface and bulk material characterization of white ProRoot MTA and two Portland cements. Dent Mater 2005;21(8):731-738

31 Duarte MAH, Alves de Aguiar K, Zeferino MA, et al. Evaluation of the propylene glycol association on some physical and chemical properties of mineral trioxide aggregate. Int Endod J 2012;45(6):565-570

32 Salem Milani A, Froughreyhani M, Charchi Aghdam S, Pournaghiazar F, Asghari Jafarabadi M. Mixing with propylene glycol enhances the bond strength of mineral trioxide aggregate to dentin. J Endod 2013;39(11):1452-1455

33 Teixeira CS, Felippe MC, Felippe WT. The effect of application time of EDTA and $\mathrm{NaOCl}$ on intracanal smear layer removal: an SEM analysis. Int Endod J 2005;38(5):285-290

34 Siqueira JF Jr, Batista MM, Fraga RC, de Uzeda M. Antibacterial effects of endodontic irrigants on black-pigmented gram-negative anaerobes and facultative bacteria. J Endod 1998;24(6):414-416

35 Nery MJ, De Souza V, Holland R. Reação do coto pulpar e tecidos periapicais de dentes de cães a algumas substâncias empregadas no preparo biomecânico dos canais radiculares. Rev Fac Odontol Aracatuba 1974;3(2):245-259

36 Kim SG, Malek M, Sigurdsson A, Lin LM, Kahler B. Regenerative endodontics: a comprehensive review. Int Endod J 2018; 51(12):1367-1388

37 Akcay H, Arslan H, Akcay M, Mese M, Sahin NN. Evaluation of the bond strength of root-end placed mineral trioxide aggregate and Biodentine in the absence/presence of blood contamination. Eur J Dent 2016;10(3):370-375

38 Islam I, Chng HK, Yap AU. Comparison of the physical and mechanical properties of MTA and portland cement. J Endod 2006;32(3):193-197

39 Hwang YC, Lee SH, Hwang IN, et al. Chemical composition, radiopacity, and biocompatibility of Portland cement with bismuth oxide. Oral Surg Oral Med Oral Pathol Oral Radiol Endod 2009;107(3):e96-e102

40 Vivan RR, Zapata RO, Zeferino MA, et al. Evaluation of the physical and chemical properties of two commercial and three experimental root-end filling materials. Oral Surg Oral Med Oral Pathol Oral Radiol Endod 2010;110(2):250-256 